\title{
ORGANIZATION OF FORMICIDAE AND ITS ROLE IN THE ECOSYSTEM OF BHUIKOT FORT, AHMEDNAGAR
}

\author{
S. L. Pawar \\ Department of zoology, Dada Patil Mahavidyalaya, Karjat, Ahmednagar \\ ${ }^{*}$ Corresponding Author: mail: Pawar.suman3@gmail.com
}

Communicated : 23.02 .20

Revision : 7.03.2020 \& 18.4.2020

Accepted : 23.05 .2020

Published: 30.05 .2020

\begin{abstract}
Ants contribute a striking component of terrestrial biodiversity and are the most contradictory group among all social insects. These acts as an ecosystem engineers. They play very important role in the ecosystem by improving the soil texture and assisting in the decomposition process of the organic components. Being a communal creature, ants validate a special interest in the study of their behavior, species variation, social behavior and high mass. All these factors make higher contribution of the formicidal biomass on the earth. Ants have achieved surprising ecological importance and dominance in terrestrial ecosystem. These successful components of ecosystem can be the good indicators of the health of the ecosystem. Investigative studies and theoretical data on role of ants in ecosystem are minimal compared to other animals, especially in India. Ants can be studied practically everywhere like interiors of agricultural fields, forests or in underground soil and upto the houses. Present investigation is to look at their distribution across variety of habitat types and to study their role in maintenance of that ecosystem. Present investigation gives the results of species diversity of ants and richness of the soil from some selected localities around the famous land fort of Ahmednagar. Present study will help in studying the significance of their organizational functioning in the ecosystem studied.
\end{abstract}

Key words:- Biomass, Ecology, Ecosystem, Investigation, Indicator.

\section{INTRODUCTION}

The Bhuikot fort of the historical city of Ahmednagar is located in Bhingar cantonment area which have occupied a considerable land mass having $19.0964^{\circ} \mathrm{N}, 74.7557^{\circ} \mathrm{E}$ latitude and longitude respectively and has different soil types with diverse vegetation. Water reservoirs like Kapurwadi Lake, Bhatodi Paragaon Lake, Brahmatale are some of the water reservoirs at very close distance from this historical place providing a satisfactory underground water level in the surrounding area. Bhingar cantonment has a special attention in development of public parks, green zones, green islands, triangular gardens as well as it has developed a remarkable green zone as biodiversity park very close to the famous Bhuikot or land Fort of Ahmednagar by using the waste water of Bhingar Nala. This park has several plant species, shrubs, herbs, grassland, small water reservoir for the birds. The efforts made by the cantonment has added floral as well as the faunal diversity in this area. The ants are the bioindicators of ecosystem and are the most common insects found in the fort ecosystem and hence attract much attention of the workers. The investigator has taken the opportunity for carrying an initiative to study the occurrence of the ants fauna of the Bhuikot or land Fort of Ahmednagar. The ants are the major component of the studied ecosystem as they are playing important role in the ecosystem engineering 8 . The occurrence of members of the family Formicidae from the order hymenoptera is taken into consideration in the present investigation. Occurrence of the members of the Formicidae indicates the well being of that ecosystem as they are successful 
soil indicators \& indicates the richness of the soil \& its correlation with the plant species in that soil. Present study is carried out in these areas from where the ant samples have been collected.

\section{MATERIALS AND METHODS:}

The Biodiversity park \& Bhuikot or land Fort is a military developed and maintained areas with thick vegetation and hence provides suitable ecological environment for insect communities which can be used to make an assessment of the status of ant biodiversity in such man-made ecosystem. The ant sampling was carried out from each corner of the Bhuikot fort of Ahmednagar during June 2018 to May 2019 by using quadrate method.. The ants were mainly collected handpicked by using fine brushes and forceps. Trees, wooden logs and other likely places where ants colonize were looked for by concentrating on their subterranean nest (Which are either cone or mound), arboreal nest (prepared by using leaves among the trees) and nests which are constituted in or outside the stems of the plants or in dead decaying leaf litter because the construction of ant nests changes the physical \& chemical qualities of the soil by increasing its drainage capacity, aeration transformation of organic matter into nutrients $4 \& 9$. Such bioturbation occurs in the top soil as well as in the subsoil though the ant nests are subterranean or a mound.

The collected samples were preserved in $70 \%$ alcohol. The photographs of these ants were taken for identification by using the taxonomic keys of $1,2,3 \& 6$. The identification was done upto the species level.

\section{RESULT AND DISCUSSION:}

From the above results it is concluded that species richness, diversity and abundance were higher in undisturbed fort site. In the present investigation 23 species were identified representing 5 subfamilies of ants in the studied ecosystem. It was observed that the subfamily myromicinae have shown its maximum occurrence $1,2 \& 3$ including its 10 species while the subfamily Formicinae have contributed with 7 species in the studied area. The subfamily Ponerinae contributed through its 3 subspecies in this ecosystem while 2 species of the sub family Dolichoerinae have shown their common and seasonal occurrence 4, 5 \& 7 respectively. Sub family Pseudomyronicinae was represented by its only one most common species. The occurrence of the subfamilies and their species is mentioned in table no. 1 .

In this ecosystem, the maximum contribution have shown by the species of subfamily myrmicinae of which its species solenopsi, geminate, pheidole watsoni, cataulacus, taprobanae have shown their most common occurrence throughout the investigation time and crematogaster subnuda have shown their seasonal occurrence while tetramorium smithi were found occasionally.

The 4 species of foramicinae have shown their common occurrence while 2 species found seasonally while Lep. Cremanotogaster ranisonneti, meranoplus bicolor, monomorium phazaonis isiota opaca found occasionally. But the only one species of family pseudomyrmicinae found throughout the investigation period.

Thus dominance of the subfamily Myromicinae was observed in the study area .It was found that the componotus copressus was common in all four corner of the study area and is a general predator but plays important role in turning of soil. The richness of the floral diversity is indicated by common occurrence of the Tetraponera rufonigra which requires microhabitats of suitable trees. The occurrence of the member species of the subfamily Ponerinae indicates the availability of food in the form of prey organism as these 
species are predators. The occurrence of crematogaster species indicates the high productivity of canopy foliage in the studied ecosystem. 6

Thus the present investigation shows that the studied area has shown diversity of ants with diverse vegetation. It has shown a very efficient role of ants in the grassland found in the studied area. The higher ant diversity was recorded in the months of April and May 2019. It is also estimated that the most dominant group of ant was subfamily Myrmicinae $2 \& 3$ which was followed by Subfamily Formicinae.

\section{REFERENCES:}

Bolton,B.(1994):Identification guide to the ant genera of the world. Cambridge, Massachusetts: Harvard University press,222 pp

Chavan A. \& Pawar S. (2011): Distribution and diversity of ant species (Hymenoptera: Formicidae) in and around Amravati city of Maharashtra, India. World Journal of Zoology 6 (4): pp 395-400.

Chavan R. \& Patkar N. (2014): Diversity of Ants (Hymenoptera: Formicidae) From Undisturbed and Disturbed Habitats of Great Indian Bustard Wildlife Sanctuary, International Journal of Scientific Research. Vol 3 pp 398-401
Davidson D.W. (1997): The role of resource imbalance in the evolutionary ecology of tropical Arboreal ants. Biological Journal of the Linnean Society 61: 153181.

Gadagkar, R. P. Nair, K. Chandrashekhar and D.M. Bhat, (1993). Ant species richness in some selected localities in Western Ghats, India. Hexapoda, 5: 70-94.

Holldobler,B. and Wilson,E.O.(1990): The Ants. The Belknap Press of Harvard University Press, Cambridge Massachusetts.

Kumar, S. K. T. Shrihari, P., Nair, Varghese, T. \& Gadagkar, R. (1997). Ant species richness at selected localities of Bangalore. Insect Environment 3: 3-5.

Mathew,R.and R. N. Tiwari (2000):Insects: Hymenoptera: Formicidae, State fauna Series 4: Fauna of Meghalaya 7: pp 251409.

Pachpor, T.\& Y. Ghodke. 2000-2001. Ant genera distribution across Pune city. Journal of Ecological Society 13\&14: 1822 . 
I J R B A T, Issue (VIII), Vol. II, May 2020: 100-103

e-ISSN $2347-517 X$

Table: 1 Occurrence of family Formicidae $\&$ its subfamilies and their species at the study site

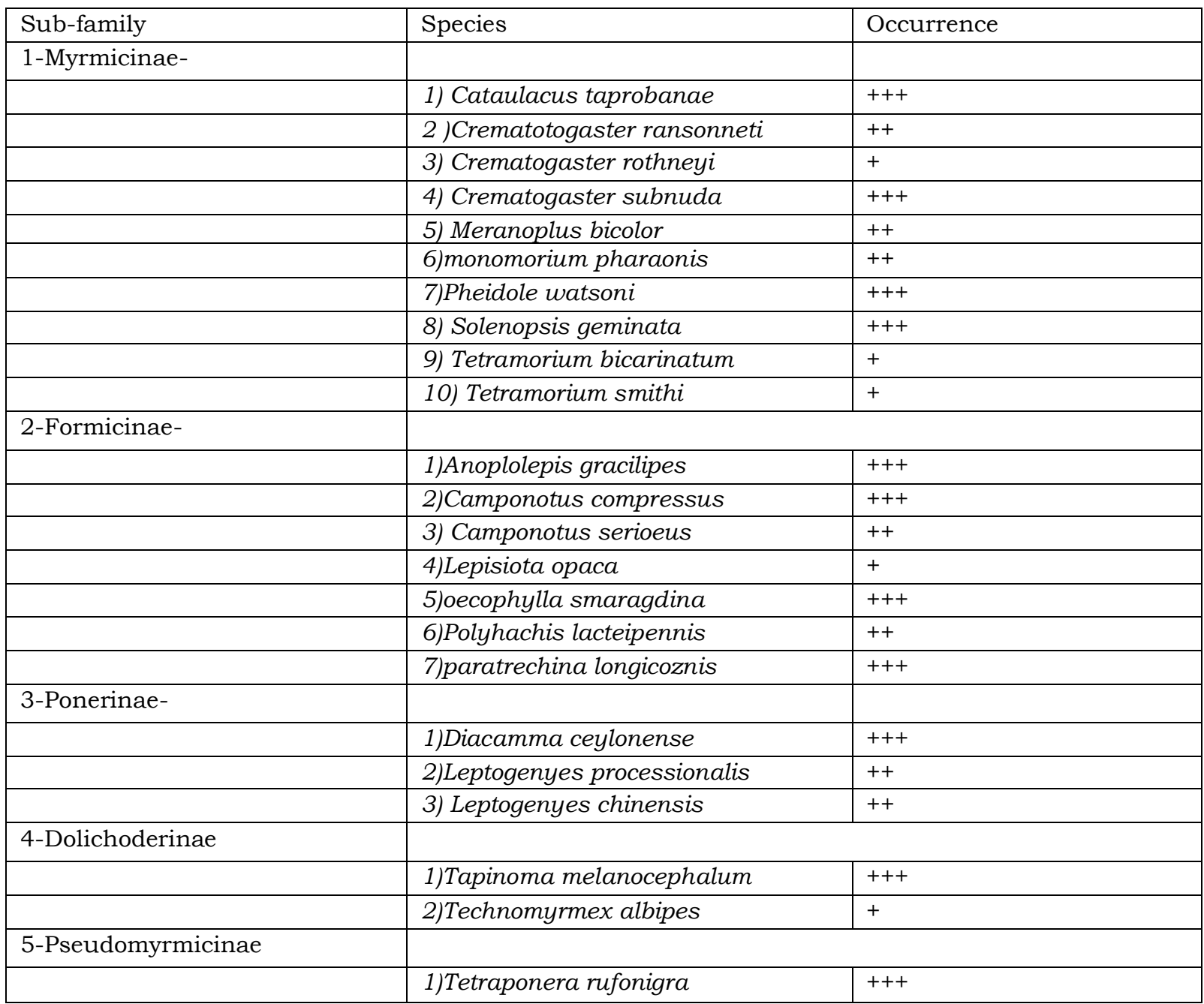

Table -2 showing percentage of occurrence of the ant species

\begin{tabular}{|l|l|l|l|}
\hline Sr no. & Name of subfamily & No. of species found & Percentage of occurrence \\
\hline 1 & Myrmicinae & 10 & 43.47 \\
\hline 2 & Formicinae & 07 & 30.46 \\
\hline 3 & Ponerinae & 03 & 13.04 \\
\hline 4 & Dolichoderinae & 02 & 08.69 \\
\hline 5 & Pseudomyrmicinae & 01 & 04.34 \\
\hline
\end{tabular}

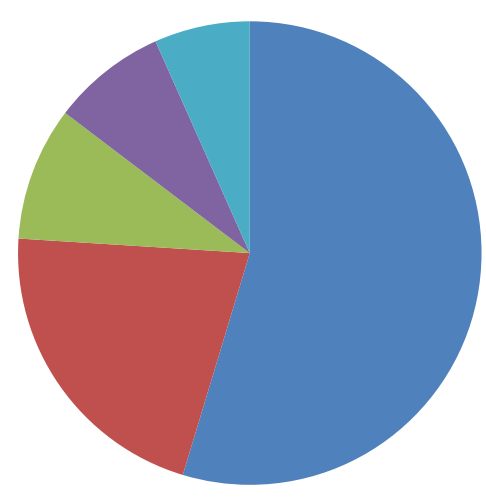

- Myrmicinae

- Formicinae

- Ponerinae

Dolichoderinae

- Pseudomyrmicinae 